\title{
Urban Containment: An Effective Tool for Environmental Protection?
}

\author{
Maria A. Cunha-e-Sá* \\ Sofia F. Franco**
}

January $31^{\text {st }}$, 2012

\begin{abstract}
This paper examines the effectiveness of urban containment policies to protect forestland from residential conversion and to increase the provision of forest public goods in the presence of irreversible investments and policy uncertainty. We develop a model of a single landowner that allows for switching between competing land uses (forestry and residential use) at some point in the future. Our results show that urban containment policies can protect (even if temporarily) forestland from being developed but must be supplemented with policies that influence the length and number of harvesting cycles if the goal is to increase nontimber benefits. The threat of a development prohibition creates incentives for preemptive timber harvesting and land conversion. In particular, threatened regulation creates an incentive to shorten rotation cycles to avoid costly land-use restrictions. However, it has an ambiguous effect on forestland conversion as the number of rotation cycles can also be adjusted to maximize the expected returns to land. Finally, in the presence of irreversibility, forestland conversion decisions should be done using real option theory rather than net present value analysis
\end{abstract}

Keywords: urban development; forest externalities; rotation cycles; urban conversion; UGB; Greenbelt

JEL Classification \#: Q23, R11, R14

\footnotetext{
*Mailing Address: Nova School of Business and Economics (Nova SBE), Universidade Nova de Lisboa, Campus de Campolide P-1099-032, Lisboa, Portugal. Email: mcunhasa@novasbe.pt, Phone:+ 351213801600. **Corresponding author. Nova School of Business and Economics (Nova SBE), Universidade Nova de Lisboa, Campus de Campolide P-1099-032, Lisboa, Portugal. Email: sfranco@novasbe.pt. Phone: +351-21380-1600 Ext: 1353. And UECE-Research Unit on Complexity and Economics, Lisboa, Portugal.
} 


\section{Introduction}

\subsection{Motivation}

Since the Second World War, America's forestland resources have come under increasing pressure to develop. Between 1992 and 1997, over 11 million acres of private forest, cropland and open space were converted to urban and other developed uses across the contiguous United States, as population and personal incomes increased significantly. An additional 49.7 million acres of forest is projected to be converted to urban use by 2062 (Alig et al. (2010)).

Several state and local governments have responded to the adverse effects associated with rapid urban growth and increasingly land-consumptive development patterns by creating a wide range of policy instruments designed to manage urban growth and protect open space. Of the array of growth management techniques, urban containment policies such as Urban Growth Boundaries (UGBs), Urban Service Boundaries and Greenbelts are considered by some to be a promising approach.

The rationale behind urban containment policies is the existence of market failures in land allocation. Many land uses generate externalities, which may distort market returns to alternative land uses (Brueckner (2000a, 2001)). For example, forestland produces both market and nonmarket benefits. While timber has a market price, most forest services do not have a market price to reflect the benefits they provide to society. Nonmarket benefits associated with private forestland include scenery, recreation, wildlife habitat, water resource protection, among others. As a result, market prices of forestland may be distorted below the social values. Another market failure is the under pricing of urban infrastructures which occurs because developers do not bear all the public infrastructure costs generated 
with new development at the rural-urban fringe. As a result, private costs of land development are often distorted below the social costs.

Intuitively, urban containment policies can have environmental impacts by forbidding or delaying development outside containment boundaries, and focusing demand for urban development areas within them. However, land management practices can also affect undeveloped land as ecological resources that provide wildlife habitat and other environmental benefits. For example, less intensive management and less frequent harvesting of remaining private forestlands can alter or improve certain habitat conditions on some private forestlands. Environmental protection is thus linked not only to protection of undeveloped land from conversion to irreversible land uses (such as residential, commercial, and industrial development) but also to land management practices. This raises the following question: Do urban containment policies actually improve the provision of environmental services and goods from private land?

The goal of this paper is to examine the effectiveness of urban containment policies to protect forestland from residential development and to increase the provision of forest public benefits in the presence of irreversible investments and policy uncertainty.

Building on the framework of Capozza and Helsley (1989) and Hartman (1976), we develop a model of a forest landowner operating in an open-city environment that allows for switching between competing land uses at some point in the future. The model incorporates public nontimber benefits of an even-aged forest in addition to the value of timber when it is harvested. Nontimber benefits are related to the forest stand age. Timber is exploited on a multiple rotation model à la Faustmann. Conversion to residential use is irreversible. 
Within this setup, we study the impacts of actual development prohibitions by urban containment policies on the conversion of forests to residential use and forest management practices, which in turn have an impact on the production of public benefits. We consider two types of forest management practices: the length of a harvesting cycle (or rotation date) and the number of harvesting cycles. Following Turnbull (2004, 2005), we also examine how regulatory uncertainty affects private forestland conversion and forest management behavior. Landowners know with certainty the type of land use regulation that will affect their land but are uncertain towards when the development prohibition will take place.

Our analysis reveals several interesting findings. Both private forest management practices and the timing of land conversion from forest to residential use do not respond to nontimber benefits in the socially optimal way. There are two reasons why this happens.

First, since the landowner does not obtain commercial profits for nontimber benefits, he lacks the incentives to manage his land on behalf of such benefits. As a result, the rotation date choice and conversion timing are not efficient and a policy intervention can raise welfare.

Whether a private landowner converts earlier than what is socially optimal depends on the type of forest externality and on the relationship over time between those externalities, timber revenues and residential rents. Furthermore, even under certainty, private forestland conversion can be optimally delayed beyond the point where net present values become nonnegative, if residential land rents grow over time and irreversibility of residential investments is accounted on land use decisions. This in turn implies that regardless of the presence of nontimber benefits, conversion of forestland to any other land use should be based on real option theory rather than on the traditional net present value rule. 
Second, in the presence of a threat of development prohibition on the property, the forester has an incentive to reduce the risk of regulation, and the associated risk of financial loss, by decreasing the potential environmental value of the land. The longer the landowner waits before harvesting, the more likely that he will lose the possibility to convert land. The threat, rather than the regulation itself, creates an incentive to shorten rotation length to avoid costly land-use restrictions but has an ambiguous effect on conversion date even under risk neutrality. The impact of a threat on the timing of land development is ambiguous because the landowner can adjust the number of rotation cycles. ${ }^{1}$ In fact, the optimal response of the landowner may be to have more rotation cycles but of shorter length. ${ }^{2}$ In this case, the increase in the number of rotation cycles has a countervailing effect on the incentive to anticipate forestland conversion due to preemptive timber harvesting.

Finally, we also show that protecting forestland from being converted to an irreversible land use may not be sufficient to increase the level of nontimber benefits. For regulated land, both an UGB and a Greenbelt unambiguously postpone the time of land development (temporarily or permanently, respectively) but have an ambiguous effect on forest management practices. The choice of rotation length can affect stand-age-dependent benefits and therefore it is not certain whether urban containment policies result in a socially efficient level of environmental protection. If the goal is to increase nontimber

\footnotetext{
${ }^{1}$ This result contrasts with the conclusion of Turnbull $(2004,2005)$ that unregulated land subject to regulatory risk is generally developed more quickly than is socially efficient.

2 This is almost certainly to be the case if land is potential habitat for an endangered species or if a mature forest can increase demand for outdoor recreation which in turn can trigger regulation to protect open space. In contrast, if the land harbors no potential for endangered species or any other environmental value but is under a threat of development prohibition by a growth management policy, then the length of a harvesting period and number of rotation cycles almost assuredly reinforce each other in the direction of earlier conversion. In this sense, growth controls could have the unintended short-run effect of inducing forestland conversion to residential use.
} 
benefits from private forestlands, UGBs and Greenbelts should be supplemented with policies that affect timber harvest activity.

Stated more generally, both land use change and land management practices affect the amount of public good provision from open space protection. Thus, any policy that focuses on land, but overlooks the management part of a private working landscape such as farmland or forestland is bound to fail in providing the efficient level of environmental benefits from open space protection. Moreover, land use change decisions based on the net present value methodology can lead to inefficient decisions. In contrast, real option theory can not only provide a lower bound for compensation payments as well as lead to efficient investment decisions. The reason is because real option theory takes into account future management practices, irreversibility as well as changes in the regulatory environment. ${ }^{3}$

Next, we provide a brief review of the literature in order to place our paper in context.

\subsection{Related Literature}

Our paper is related to three strands of the theoretical literature. One strand is the literature on urban growth models with perfect foresight, such as Capozza and Helsley (1989, 1990) and Capozza and Li (1994, 2002). The second strand is the literature on forest management practices in the presence of nontimber benefits, such as Hartman (1976) as well as Swallow et al. (1990). A third strand is the literature on the effects of land use policies on development timing, such as Turnbull (2002, 2004, 2005) and Brueckner (1990).

\footnotetext{
${ }^{3}$ For more comparisons between the net present value and real option theory approaches see Dixit and Pindyck (1994). For an application of the real option theory to forest management decisions see Conrad (1997) and Reed (1993). Conrad (1997) values forest resources when the amenity value of old-growth follows a geometric Brownian process. Reed (1993) considers the decision to cut or preserve an old-growth forest when timber and amenity values follow a geometric Brownian process. None of these two studies takes into account conversion of forestland to an alternative irreversible land use or policy uncertainty.
} 
While the increasing economic importance of open space and forest amenities (Leggett and Bockstael (2000), Tyrainen and Miettinen (2002), Geoghegan (2002), Irwin (2002)) and the implications of nontimber benefits for harvesting within the traditional Faustmann framework (Hartman (1976), Strang (1983), Swallow et al. (1990)) are well understood, the feedback effects between urban development and forestland changes are not.

Theoretical models of forest management practices (Hartman (1976), Strang (1983), Swallow et al. (1990)) do not account explicitly for the potential conversion of forestland to an alternative use (such as agriculture or urban use) at some point in the future or for policy uncertainty. However, when conditions of irreversibility, price uncertainty and ability to delay exist, decisions entail an implicit option for the value of waiting (Capozza and Sick (1994)). In addition, the risk of a regulation creates incentives for investors to attempt to reduce the risk of exposing their land and investments to regulation, leading to distortions in the pace and pattern of investment (Turnbull $(2004,2005)$ ).

On the other hand, models of urban development have permitted consideration of key dimensions of decision making, for example intertemporal decisions (Arnott (1980), Fujita (1982), Capozza and Helsley (1989)) and house-price uncertainty (Capozza and Helsley (1990), Capozza and Li (1994, 2002)), and examined how these features influenced the resulting price gradient and land use pattern. Even though these models are forwardlooking it is assumed that the rental value of undeveloped land (typically agriculture) is constant over time and exogenous. Therefore, these models are not able to examine endogenous interactions between land management practices associated with alternative uses and development decisions or examine the impacts of land management decisions 
(extract of resources) on the provision of open space benefits. Yet, if natural resources are extracted, or land is converted to an alternative land use, amenity values are lost. ${ }^{4}$

Building on the framework of Capozza and Helsley (1989) and Hartman (1976) this paper develops a model of a single forest landowner that allows for switching between two competing land uses (forestry and residential use) at some point in the future. We examine development intensity when land is under residential use and the length and frequency of harvesting cycles when land is used as forest. In our model the rental value of undeveloped land is endogenously determined. These features allow us to examine how endogenous feedbacks between alternative land-uses impact development decisions and land management practices. It also allows to study the impacts of both land use change (through conversion) and land use management decisions on the provision of open space benefits. With regard to the impact of uncertainty on investment and development decisions, this paper departs from Capozza and Li (1994, 2002) and Capozza and Helsley (1990) by examining future use uncertainty on land management decisions.

A third strand of the literature that relates to our work builds upon Capozza and Helsley (1989, 1990) and examines the effects of an UGB or a Greenbelt on urban development in a dynamic setting (Turnbull (2002, 2004, 2005), Brueckner (1990)). Brueckner (1990) examines how restrictions on the expansion of an UGB in a dynamic open city environment could increase land values and social welfare in the presence of a population externality. Turnbull (2002, 2004) investigate how private property rights under threatened regulation affect the timing and density of development in an urban land market. Turnbull (2002) focus on policies restricting allowed uses, while Turnbull (2004) focus on development timing restrictions. Turnbull (2005) provides an overview on how land use regulations

\footnotetext{
${ }^{4}$ For an overview on urban growth models with perfect foresight see Brueckner (2000b).
} 
affect the pace and pattern of urban development. ${ }^{5}$ Yet, none of these studies examine the effects of threatened regulation on management practices and conversion decisions when the returns of competing uses are interdependent. Moreover, these studies do not account for environmental externalities directly linked to management land practices. As a result, the extent to which landowners can engage in preemptive behavior to avoid potential landuse regulations cannot be fully examined within these frameworks. In contrast, our model allows us to examine preemptive behavior associated with land conversion and/or management practices of a parcel of land. It also allows us to explore the effects of zoning policies on land use and natural resource management.

The rest of our paper is organized as follows. Section 2 presents the analytical model and derives both the market conversion and rotation dates and the social benchmark. Section 3 examines the environmental impacts of an unanticipated development prohibition. We also examine the effects of policy uncertainty on private land development and forest management practices. Finally, section 4 offers conclusions.

\section{The Analytical Model}

\subsection{Assumptions}

Suppose that at time $t=0$ there is a parcel of bare land located $x$ miles from a central business district (CBD) and that an even-aged forest stand is planted at time zero. Let $c_{0}$ represent the initial planting costs in bare land. A forest provides a flow of public nontimber benefits while standing in addition to the value of timber when it is harvested.

\footnotetext{
${ }^{5}$ In Turnbull $(2004,2005)$ the underlying externality that justifies the land use regulation is associated to the existence of undeveloped land and disappears once the land is developed.
} 


\section{Timber Benefits}

Timber is exploited based on a multiple rotation model with clear-cut harvesting. ${ }^{6}$

If trees are planted at $t=0$ and harvested at $t=T$, then $t$ represents the age of the trees and $T$ is the harvesting age. Note that $T$ is also the length of the harvesting cycle $[0, T]$ and is denoted by rotation date. At each rotation date, the forest owner immediately plants the next age class. The sequence of jump points, $j T$, with $j=1,2, \ldots ., K \leq \infty$, determines the stand rotation periods. All rotation cycles have the same length. ${ }^{7}$

Timber prices, $p$, and harvesting and replanting costs, $c$, are assumed to be exogenous and constant over time. Let $v(T)$ represent the volume of commercially valuable timber biomass on a forest stand over the rotation age $T$, which is assumed to be a strictly concave function. The present value at time $t=0$ of the financial reward from harvesting the stand at $t=j T$ is given by:

$$
(p v(T)-c) e^{-r j T}, \mathrm{j}=1, \ldots, \mathrm{K}
$$

where $r$ is the discount rate and $(p v(T)-c)$ is the value of timber net of harvesting and replanting costs, which is constant over rotation cycles.

\section{Nontimber Benefits}

\footnotetext{
${ }^{6}$ Clear-cut harvesting is a harvesting technique that involves harvesting all the trees in one area at one time.

${ }^{7}$ Note that $j=1,2, \ldots, K$ is an index that pertains to the ordinal sequence of harvests. For example, if the rotation date is 20 years, then harvests occur at each date $t=20,40,60, \ldots$. since the interval between successive harvests is constant over time.
} 
Nontimber benefits are a function of the age of the trees. Let $F(t)$ denote the value of nontimber benefits from the standing forest of age $t .{ }^{8}$ It is usually assumed that $\frac{\partial F(t)}{\partial t}>0$, indicating that a mature forest provides more nontimber benefits than a young forest. However, this assumption has been challenged by Englin and Klan (1990) and Swallow et al. (1990) who argue that nontimber benefits may follow any time path, depending on the externalities considered. ${ }^{9}$ In the analysis that follows, the only restriction placed on $F(t)$ is differentiability. The present value of amenity services from the forest stand under a single harvest cycle of length $T$ is given by:

$$
\int_{0}^{T} F(t) e^{-r t} d t
$$

\section{Conversion to Residential Use}

At each point in time, the forest landowner must decide to harvest the forest and replant the land, delay the harvest decision or decide to harvest the forest and convert the land into residential use. Let $T^{D}$ represent the time of land development, also denoted by conversion date. In order to make the problem more tractable we postulate that conversion of forestland to residential use occurs at the end of a rotation cycle, that is,

\footnotetext{
${ }^{8}$ The value of some nontimber benefits such as recreational benefits, aesthetic views, watershed protection and carbon storage may depend on the distance to the CBD, so that we would have $F(t, x)$. For simplicity we assume that nontimber benefits do not depend on distance to the CBD.

${ }^{9}$ Some wildlife species are best adapted to early plantation stages of forest (as in the case of moose) or forage production for cattle grazing. Other wildlife species (including trout) are more adapted to mature forests and greater scenic beauty can also be associated to old growth forests. Swallow et al. (1990) present alternative functional forms to capture the effects of age on various types of nontimber benefits. There are nevertheless other nontimber values of forestlands for which it is not the age of the trees that is important, but rather, the rate of tree growth. For simplicity, we do not consider those cases in our analysis. However, one example of such nontimber benefits is carbon sequestration. For a theoretical discussion on how the Faustmann harvest age is affected by the inclusion of carbon sequestration benefits see Van Kooten et al. (1995).
} 
$T^{D}=K T, 0 \leq K \leq \infty .{ }^{10}$ Forestland conversion involves a one-time cost $D$ for clearing the land. Residential development once undertaken is irreversible. Land, housing and input markets are competitive markets.

\section{Housing Bid Rent Function}

A representative household enjoys utility from housing, $q$, and a composite consumption good, $g$. Households' preferences are represented by a strictly quasi-concave utility function $U(g, q)$. We set the price of the composite good equal to 1 and housing demand is also fixed at one unit. The household budget constraint is given by $g+b=y(t)-z(t) x$, where $x$ denotes distance to the CBD, $z(t)$ commuting costs per mile at time $t, b$ is the rental price of housing and $y(t)$ denotes income earned at time $t$.

The housing bid rent function is determined via the no arbitrage condition, which implies that in equilibrium, utility must be identical regardless where an urban resident lives; otherwise, some urban residents will have an incentive to move. ${ }^{11}$ The housing bid rent function is defined as:

$$
b(t, x)=b(y(t)-z(t) x, 1, \bar{U}(t))
$$

Equation (3) describes the maximum rent per unit floor area that a household is willing to pay at distance $x$ from the CBD if it is to receive a fixed level of utility $\bar{U}(t) \cdot \bar{U}(t)$ is assumed to be exogenous. It is also assumed that $y(t), z(t)$ and $\bar{U}(t)$ vary over time in a

\footnotetext{
${ }^{10}$ This assumption is quite plausible given that working forests are associated with long rotation cycles. As noted in (1) revenues from forestry are received after a multi-year rotation period. This delay occurs because growth in stand value is non-linear. As a result optimal rents cannot be extracted if harvest occurs before the optimal rotation period. Therefore, early harvest implies an opportunity cost that varies with the stand's lifetime.

${ }^{11}$ See Appendix-B for further details on how to derive the housing bid rent function.
} 
way that ensures that $\frac{\partial b(t, x)}{\partial t}>0$ so that housing bid rents rise over time. ${ }^{12}$ Moreover the housing bid rent is a decreasing function of distance from the CBD, $\frac{\partial b(t, x)}{\partial x}=-z(t)<0$.

\section{Residential Development Density}

Housing floor space is produced with capital and land according to a strictly concave, constant returns to scale production function. The intensive form of the production function is written as $h(S)$, where $S$ is capital per unit of land, referred to as structural density, and $h$ satisfies $\frac{\partial h(S)}{\partial S}>0$ and $\frac{\partial^{2} h(S)}{\partial S^{2}}<0$. At each point in time, the landowner chooses the amount of structural density $S$ to maximize the gross profit per unit of land at location $x$, while taking into account (3):

$$
\underset{S}{\operatorname{Max}} b(y(t)-z(t) x, 1), \bar{U}(t)) h(S)
$$

The first-order condition for the maximization problem (4) is given by:

$$
b(y(t)-z(t) x, 1, \bar{U}(t)) \frac{\partial h(S)}{\partial S}=0
$$

Density condition given by equation (5) requires that more density should be added up to the point where the value of incremental gross profit from greater density equals zero. The solution to equation (5) gives structural density as a function of $t$ and $x$,

\footnotetext{
12 This requires that disposable income $y(t)-z(t) x$ is increasing sufficiently rapidly (or falling sufficiently slowly) relative to utility.
} 
$S(t, x)=S(y(t)-z(t) x, 1, \bar{U}(t))$. Note that residential development becomes denser over time

since housing bid rents increase smoothly over time: $\frac{\partial S(t, x)}{\partial t}=-\frac{\frac{\partial b(t, x)}{\partial t} \frac{\partial h(S)}{\partial S}}{b(t, x) \frac{\partial^{2} h(S)}{\partial S^{2}}}>0$.

\section{Residential Land Rent Function}

Since the urban land market is competitive, the residential land rent function, $R(t, x)$, is given by the zero profit condition, which implies:

$$
R(t, x)=b(y(t)-z(t) x, 1, \bar{U}(t)) h(S(t, x))
$$

where $S(t, x)=S(y(t)-z(t) x, 1, \bar{U}(t))$. Since housing bid rents and development intensity increase over time, residential land rents also grow over time.

\subsection{The Social Planner's Problem}

The goal of the social planner is to choose the rotation length, $T \geq 0$, and number of rotation cycles, $K \geq 0$, in order to maximize the social present value of land taking into account (6), $T^{D}=K T$ and $K \in \mathrm{N}$. The social value of convertible forestland at time $0, V^{S P}$, is given by: ${ }^{13}$

$$
V^{S P}(K, T)=-c_{0}+\frac{1-e^{-r K T}}{1-e^{-r T}}\left[\frac{(p v(T)-c)}{e^{r T}}+\int_{0}^{T} F(t) e^{-r t} d t\right]+\int_{K T}^{\infty} R(t, x) e^{-r t} d t-D e^{-r K T}
$$

Our framework differs from the conventional forest economic model by incorporating in (7) the possibility to convert forestland to residential use at some point in the future. When the landowner has perfect foresight and conversion to an alternative use is irreversible, the optimal rotation length can no longer be determined in isolation. Instead,

\footnotetext{
${ }^{13}$ By choosing $T$ and $K$, the social planner chooses the rotation date and the conversion date.
} 
the rotation length must be optimized together with development timing. The optimal solution then combines aspects of the conventional forest economic model with a model of irreversible urban growth under perfect foresight.

The first two terms on the right-hand-side of (7) represent the present value of forest rents. It includes the present value of the net revenues from timber exploitation at the end of each rotation and the present value of nontimber benefits from a standing forest up to the date of conversion net the initial planting costs. ${ }^{14}$ The two last terms of (7) are the present value at time $t=0$ of future residential rents from the date of conversion onward net the present value of conversion costs at time $K T$.

Table 1: Appendix-A presents the conventional criteria applied to the problem of choosing the optimal rotation length under certainty, including maximizing the net present value of timber income (Faustmann rotation), and maximizing the present value of timber and nontimber benefits (Hartman rotation). Table 1 also summarizes the first-order conditions for later comparison with our results.

\section{The Social Rotation Date}

Differentiating (7) with respect to $T$, for a given $K$, and rearranging the terms, yields:

\footnotetext{
${ }^{14}$ Nontimber benefits over one harvest cycle are given by the sum of the annual nontimber benefits received at rate $F(t)$, compounded as timber grows to age $T$. We can easily modify our model to include also nontimber benefits from the existence of forestland. Let $\delta(\mathrm{t}), 0 \leq t<K T$ be the open space externality at time $t$. Adding $\int_{0}^{K T} \delta(t) e^{-r t} d t$ to (7) would thus capture an open space externality from the existence of undeveloped land. However, our fundamental model results would not change with the inclusion of this type of nontimber benefit.
} 


$$
\begin{aligned}
& p \frac{\partial v(T)}{\partial t}=\frac{r}{1-e^{-r T}}(p v(T)-c)+\left[\frac{r}{1-e^{-r T}} \int_{0}^{T} F(t) e^{-r t} d t-F(T)\right]+ \\
& +\frac{K\left(e^{r T}-1\right)}{e^{r K T}-1}\left[[R(K T, x)-r D]-\frac{r}{1-e^{-r T}}\left[(p v(T)-c) e^{-r T}+\int_{0}^{T} F(t) e^{-r t} d t\right]\right]
\end{aligned}
$$

Equation (8) represents the socially optimal rotation length condition for a given number of rotation cycles. This condition can be interpreted as a Faustmann-Hartman like equation that includes a new component associated with the switch to residential use at time KT . We denote this new component by the "switching balance".

The left-hand side of (8) is the marginal benefit of waiting out the harvesting, which consists of the increase in the value of timber if harvesting is delayed one year. The righthand side of (8) is the marginal cost of waiting out the harvesting and comprises three parts.

The first term represents the cost of holding the growing stock $(\operatorname{rpv}(T))$ plus the cost of holding the land for future rotations $\left(r \frac{p v(T)-c}{e^{r T}-1}-c\right) .^{15}$

The second term represents the "externality balance” found in the Hartman framework, which compares the value of nontimber benefits at the harvesting time $(F(T))$ and the discounted value of the accumulated nontimber benefits associated with the growth of the trees until felling $\left(\frac{r}{1-e^{-r T}} \int_{0}^{T} F(t) e^{-r t d t}\right)$. The sign of this externality balance depends on the shape of the nontimber benefits function, $F(t)$. When larger external benefits are associated with larger and older trees, the externality balance is negative. In this case, it is optimal to postpone harvesting. In contrast, when nontimber benefits are larger for smaller and

\footnotetext{
${ }^{15}$ The cost of holding the growing stock is the amount of interest payment the landowner would get if he sells the stand at time $T$ and invests the money at interest rate $r$ for one year. The cost of holding the land for future rotations represents the soil rent the landowner should charge himself for waiting one more year.
} 
younger trees, the externality balance is positive, and shortening the harvesting time is optimal.

Together, the first two terms on the right-hand side of (8) assume land will be kept as forest through an infinite sequence of harvests. When $K \rightarrow \infty$, equation (8) is reduced to the first-order condition for the Hartman setup. ${ }^{16}$ When in addition, nontimber benefits are zero, equation (8) is reduced to the first-order condition for the Faustmann setup. ${ }^{17}$ Table 1: Appendix-A summarizes these first-order conditions.

The third term on the right-hand side of (8) is the "switching balance" which accounts for the fact that land may not be kept forever in forest use, that is, $0 \leq K<\infty$. If land is converted at $K T<\infty$, the opportunity cost of postponing harvest assuming that land will be forested forever has to be adjusted by the timber and nontimber benefits that will not occur past the conversion date $K T$ (that is, $\left.\frac{K e^{r T} r}{e^{r K T}-1}\left[(p v(T)-c) e^{-r T}+\int_{0}^{T} F(t) e^{-r t} d t\right]\right)$. In addition, the Hartman formula in the presence of switching must also account for the opportunity cost of delaying development which is given by the present value of residential land rent net of the annualized cost of development, $[R(K T, x)-r D]$.

When the "switching balance" is positive, the net present value of residential land rents is greater than the present value of timber and nontimber benefits if land is kept under forestry management from $K T<\infty$ onwards. This implies that, for a given $K$, the social rotation length in the presence of switching is always shorter than the Hartman rotation

\footnotetext{
${ }^{16}$ In special cases, stand-age-dependent externalities may result in a socially optimal rotation length that is infinite to benefit specifies that require old-growth habitat or instantaneous to benefit species that prefer open field habitat (Hartman (1976)). Stand-age-dependent externalities can also conduct to non-convexities of the objective function in the choice variable (rotation length), so that more than one local optimum may exist when choosing the rotation length (Swallow et al. (1990)).

${ }^{17}$ The Faustmann rotation rule determines when to harvest a stand of trees when timber prices are constant by comparing the net benefits from letting timber grow to the land opportunity cost without taking into account nontimber benefits or alternative irreversible investment opportunities (see Table 1: Appendix A).
} 
length due to concavity of $v(t)$. Therefore, switching to an alternative higher valued land use in the $K T$ period may affect the choice of the social length of timber rotation. Moreover, decisions based on the Hartman rotation length do not necessarily yield the greatest net benefit to society.

\section{The Social Conversion Date}

Equation (8) implicitly defines the rotation date as a function of $K$, that is, $T(K)$. The goal of the social planner is now to choose $K \in \mathrm{N}$ to maximize $V^{S P}(K, T(K))$. Let $K^{s p}$ be the optimal number of rotation cycles. The socially optimal conversion date is given by:

$$
T^{D s p}=K^{s p} T\left(K^{s p}\right)
$$

The social land conversion rule is described as follows: convert the entire parcel of land to residential use at time $K^{s p} T^{s p}$ if and only if the following condition is satisfied:

$$
R\left(K^{s p} T^{s p}, x\right) \geq r D+r\left[\frac{e^{-r T^{s p}}}{1-e^{-r T^{s p}}}\left(p v\left(T^{s p}\right)-c\right)+\frac{\int_{0}^{T^{s p}} F(t) e^{-r t} d t}{1-e^{-r T^{s p}}}\right]
$$

According to (10) a parcel of land should be converted at time $K^{s p} T^{s p}$ when the residential land rent is no less than the flow cost of conversion plus the forgone value of forestland. The forgone value of forestland is given by the present value of the sum of harvest revenue and monetary value of nontimber benefits over an infinite time horizon after conversion. When the switching balance is positive, it is always the case that condition (10) is met in inequality implying that, for a given $K$, conversion to residential use occurs earlier than when the switching balance is zero. 
A comparison between (8) and (10) also shows there is interdependency between the conversion date and the rotation date. This implies that forest management decisions can influence the optimal development timing. Changes in harvesting decisions change the opportunity cost of residential land use and therefore, have an impact on the social optimal timing of land development. Changes in harvesting decisions may occur due to changes in timber prices $(p)$ or harvesting and replanting costs $(c)$. Different types of nontimber benefits impact differently the socially optimal rotation date and thus, the socially optimal conversion time.

Finally, if $T^{s p}=\infty$ it is never optimal to harvest the stand from a social perspective and land is kept in natural forest management forever. ${ }^{18}$ In this case, the marginal benefit of postponing harvest is always greater than its marginal costs. If $K^{s p}=\infty$ then it is never socially optimal to convert land to residential use. In contrast, if $K^{s p}=0$ and $0<T^{s p}<\infty$, it is socially optimal to convert immediately the parcel of forestland to residential use.

\subsection{The Private Landowner's Behaviour}

Private rotation date $\left(T^{p}\right)$ and private number of rotation cycles $\left(K^{p}\right)$ decisions are made to maximize the present value of future private net returns to land. The landowner receives forest rents before land is developed and residential land rents after the land is converted to residential use. The present value of future private net returns to land, $V^{P}$, is given by:

$$
V^{P}(K, T)=e^{-r T}(p v(T)-c) \frac{1-e^{-r K T}}{1-e^{-r T}}-c_{0}+\int_{K T}^{\infty} R(t, x) e^{-r t} d t-D e^{-r K T}
$$

\footnotetext{
${ }^{18}$ If forestland preservation is socially optimal this requires both $T^{s p}=\infty$ (trees are never cut) and $K^{s p}=0$ (land is never developed).
} 
Equation (11) can be re-written as:

$$
\begin{aligned}
& V^{P}(K, T)=\left[\frac{(p v(T)-c) e^{-r T}}{\left(1-e^{-r T}\right)}-c_{0}\right]+ \\
& +\left[\int_{K T}^{\infty} R(t, x) e^{-r(t-K T)} d t-\left[D+\frac{(p v(T)-c) e^{-r T}}{\left(1-e^{-r T}\right)}\right]\right] e^{-r K T}
\end{aligned}
$$

The first term on the right-hand-side of (12) is the net present value of perpetual timber returns. The second term shows the value of the landowner's option to convert the land to residential use. The value of convertible forested land is equal to the sum of the present value of timber plus an option value. This option value is the amount of compensation a well-informed landowner would require if the landowner would give up his development rights. As $K \rightarrow \infty$, (12) converges to the objective function under the Faustmann model. That is, the option value decreases as the conversion date becomes further out in the future. For forestland with no conversion potential for residential use, the option value becomes zero.

\section{Private Rotation Date}

The first order condition for the private rotation date, $T$, given a $K$, is given by:

$$
p \frac{\partial v(T)}{\partial t}=\frac{r(p v(T)-c)}{1-e^{-r T}}+\frac{K\left(e^{r T}-1\right)}{e^{r K T}-1}\left[[R(K T, x)-r D]-\frac{r}{1-e^{-r T}}\left[(p v(T)-c) e^{-r T}\right]\right]
$$

A comparison of (13) with (8) shows two interesting results. Because the private landowner fails to account for any nontimber benefits, there is a divergence between the social $\left(T^{s p}\right)$ and the private $\left(T^{p}\right)$ rotation lengths. For a given $K$, depending on the type of forest externalities, the private rotation length can be shorter or longer than the socially optimal one. For example, if larger externalities are associated with larger and older trees 
$\left(\frac{\partial F(t)}{\partial t}>0\right)$, the socially optimal rotation length will be longer than the privately optimal length. While this conclusion may not be a surprise our analysis shows that if the switching balance is positive (second term on the right-hand-side of (13)), the privately optimal rotation age $\left(T^{p}\right)$ is actually shorter than the Faustmann rotation period $\left(T^{F}\right)$ due to concavity of $v(t)$ (see also table 1 , Appendix-A). ${ }^{19}$

In addition, changes in rotation length decisions resulting from population growth or income growth (as described by increases in residential land rents) can affect forests as ecological resources that provide wildlife habitat and other benefits. ${ }^{20}$ Since nontimber benefits are a function of the age of the trees, rotation decisions affect the amount of nontimber benefits provided by the forest.

\section{Private Conversion Date}

The private optimal number of rotation cycles, $K^{p}$, is determined as the $K$ that maximizes $V^{P}(T(K), K)$ and is given by $T^{D}=K^{p} T\left(K^{p}\right)=K^{p} T^{p}$. The private landowner's optimal conversion decision rule is to convert the entire parcel of land to residential use at time $K^{p} T^{p}$ if and only if:

$$
R\left(K^{p} T^{p}, x\right) \geq r D+r \frac{e^{-r T^{p}}\left(p v\left(T^{p}\right)-c\right)}{1-e^{-r T^{p}}}
$$

where $R\left(K^{p} T^{p}, x\right)=b\left(y\left(K^{p} T^{p}\right)-z\left(K^{p} T^{p}\right) x, 1, \bar{U}\left(K^{p} T^{p}\right)\right) h\left(S\left(K^{p} T^{p}, x\right)\right)$.

\footnotetext{
${ }^{19}$ In our problem $K$ is required to be an integer number, therefore it is possible that land is converted when the switching balance is still positive.

${ }^{20}$ Kline et al. (2004) provide empirical support that population growth and urban expansion are correlated with reduced forest management and investment on private forestlands in Western Oregon, USA. Empirical studies by Barlow et al. (1998) and Munn et al. (2002) for Alabama, US and Mississippi, US, and Wear et al. (1999) for Virginia, US also suggest that harvesting and commercial forest management decline as forest landscapes become more populated.
} 
It is clear from inspection of (14) and (10) that if the private landowner fails to account for all standing values, the choice of "if when" to switch to residential use is also privately inefficient. Thus, conversion may occur more often than is socially optimal. The private incentive for earlier conversion exists regardless of the type of nontimber benefits.

Condition (14) also illustrates three interesting remarks. The first one is that a private landowner will delay conversion of forested land to residential use either because the opportunity cost increases or the net value from residential development decreases. The forester will delay conversion to residential use at time $K T$ if the value of timber net of harvesting and replanting costs $(p v(T)-c)$ increases, if he incurs large conversion costs ( $D$ increases), if urban residents incur larger commuting costs $(z(K T))$, if urban income $(y(K T))$ decreases and if his land is located far away from a CBD ( $x$ increases).

The second remark is that our conversion rule differs from the conventional conversion rule in forest economic models under certainty. The standard assumption in these models is that if conversion of forestland takes places, it takes place immediately ( $t=0)$; if it is not converted at $t=0$ then land remains under forestry forever. By letting $K=0$, it can be shown that land would be converted immediately only if $\frac{R(0, x)}{r}-D \geq \frac{e^{-r T^{F}}\left(p v\left(T^{F}\right)-c\right)}{1-e^{-r T^{F}}}$, where $T^{F}$ is the Faustmann rotation period. That is, land is converted as soon as the present value of residential development, net of conversion costs, exceeds the present value of the current use. However it maybe optimal to delay conversion in order to realise returns to forest until they are exceeded by residential returns net conversion costs, even if residential 
value already currently exceeds forested land value. ${ }^{21}$ By relying on a one period rule, the conventional forest conversion model implicitly assumes that an investment can be reversed if the market is less favourable in subsequent periods. Yet, conversion to any urban use (such as residential development) is an irreversible investment.

The value of the right to delay the conversion decision equals the cost of the mistake one commits by using the net present value rule in this setting. As long as the option value (the second term on the right-hand-side of equation (12)) exceeds $\frac{R(0, x)}{r}-D-\frac{e^{-r T^{F}}\left(p v\left(T^{F}\right)-c\right)}{1-e^{-r T^{F}}}$, it is optimal to delay conversion to period $t=K^{p} T^{p}>0$, even under certainty. Hence, in addition to the cost of conversion and the loss of timber value, there is an additional opportunity cost of converting today instead of waiting and keeping the conversion option open. This additional opportunity cost must be taken into account by the private forest landowner when deciding to convert forestland to residential or any other irreversible land use regardless of the presence of open space externalities.

Our results thus show that when the forestland conversion decision is based on real option theory rather than on the traditional net present value rule, conversion of forestland is delayed. Note also that forestland conversion can be delayed further if residential density is endogenous rather than fixed. If the landowner commits today to the currently optimal intensity, he sacrifices some revenue in the future compared with what he would obtain by

\footnotetext{
${ }^{21}$ It is advantageous for the landowner to keep the land in forestry as long as the annual returns from forestry (given by the current level of timber prices and growth rates) are higher than the returns from residential use, net of conversion costs. However, in order for forestland conversion occur it is necessary that returns to forest use do not grow at a rate larger than the growth rate of residential returns; otherwise, land will never be converted to residential use even if currently returns to residential use exceed returns to forestry because of irreversibility. It is also necessary that the landowner's discount rate is higher than the growth rate of residential returns. Otherwise, the landowner would find it optimal to delay investment indefinitely. See Table 3: Appendix-A.
} 
building at a higher residential density later. The reason is because optimal structural density is positively related to residential land rents and residential structures are irreversible investments.

Equation (14) also contrasts with the deterministic development timing condition in the existing literature on urban growth with perfect foresight and irreversible conversion (Brueckner (1990), Capozza and Helsley (1989, 1990), Capozza and Li (2002), Turnbull (2005)), which assumes an exogenous opportunity cost for urban use. Typically, these models assume a constant agricultural rent per acre as the alternative rent to urban use. In the context of our analysis, the alternative land use to urban development is endogenously determined and feedbacks on the rental value of the developed state. ${ }^{22}$

Formally, note that $T$ is a function of $K$ in (14), which implies that changes in $K$ change both the left and the right hand sides of (14). If management practices were fixed and/or exogenous so that $T$ was held constant (or exogenous), the right-hand side of (14) would be constant just like in the urban growth models, and the optimal development time would be obtained adjusting $K$ on the left-hand side of (14). ${ }^{23}$ Therefore, our conversion timing condition is more general than the one emerging from urban growth models with perfect foresight and irreversible conversion.

Table 3-Appendix-A summarizes the optimal conversion decision rules under certainty discussed in this section and show that delaying forestland conversion to residential use relative to the traditional nonnegative NPV rule can be optimal even under certainty. For

\footnotetext{
${ }^{22}$ Another feature of our model is that land conversion occurs with discrete jumps. Note that changes in the (integer) number of rotation cycles cause discrete changes in the conversion date, while changes in a constant agricultural rent cause a continuous change in the development timing.

${ }^{23}$ Note that in this case $K$ is enough to determine the optimal development timing since $T^{D}=K T$ and $T$ is held constant or is exogenous implying that the return from the alternative use is also constant/exogenous, just like in the urban growth models under perfect foresight and no uncertainty.
} 
completeness, we also present in Table 2-Appendix A the optimal conversion decision rule

in the presence of public nontimber benefits.

\section{Urban Containment Policies}

The private landowner does not take into account public nontimber benefits when deciding rotation and conversion dates. Without any form of government intervention, society faces the classic problem of suboptimal provision of a public good.

This section examines the effectiveness of a development prohibition by an actual regulation to postpone conversion of forested land into residential use and to increase the provision of nontimber benefits. We examine two types of development prohibitions: a temporary development prohibition due to imposition of a binding UGB and a permanent development prohibition due to a binding Greenbelt. ${ }^{24}$ In addition, we also examine how a development prohibition probability impacts conversion and rotation dates. Below we present the main results of our analysis. ${ }^{25}$

\subsection{Development Prohibition under Certainty}

\section{Temporary Development Prohibition}

\footnotetext{
${ }^{24}$ A Greenbelt refers to a physical area of open space (farmland or forest) that surrounds an urban area, and it is intended to be a permanent barrier to urban growth. Development is strictly regulated or prohibited on greenbelts. Greenbelts can be created by public or nonprofit purchase of open space or permanent transfer of development rights or they can be created and enforced by regulation of private property. Only a few communities in the United States have greenbelts explicitly designed to control urban growth. Boulder, Colorado is one example where such policy is in place. An Urban Growth Boundary consists of drawing a line around an urban area within which development is encouraged, often with density bonuses or minimum density requirements, to accommodate expected growth over 20 to 30 years. Land outside the boundary is generally restricted to resource uses and to very low-density residential development. In contrast to greenbelts, UGBs are not intended to be permanent. In Oregon, the Land Conservation and Development Act of 1973 requires the delineation of UGBs around all of the state's cities and around the entire Portland metropolitan area. Among Oregon cities subject to this law, Portland is the best well known city for creating a model of urban containment. For a review on urban containment policies in the US see Pendall et al. (2002).

${ }^{25}$ All mathematical derivations are provided in Appendix-B.
} 
Suppose that at $t=0$ there is already in place an UGB postponing until a specified date development of any sort on any plot of land located past a certain distance from the CBD. Let's assume that our plot of land is located outside the boundary and thus, the forest landowner cannot convert his land to residential use prior to $t(x)^{U G B}$.

The goal of the private landowner is to choose the rotation and conversion dates, $\left\{K^{c}>0, T^{c}>0\right\}$, in order to maximize the net private returns to land:

$$
V^{C}(K, T)=e^{-r T}(p v(T)-c) \frac{1-e^{-r K T}}{1-e^{-r T}}-c_{0}+\int_{K T}^{\infty} R(t, x) e^{-r t} d t-D e^{-r K T}
$$

taking into account that land can be converted to residential use at any $t \geq t(x)^{U G B}$. Land can only be converted at the end of a rotation period, therefore $K^{c} T^{c} \geq t(x)^{U G B}$.

The optimal $\left\{K^{c}, T^{c}\right\}$ under this regulation must satisfy the following conditions:

$$
\begin{aligned}
& p \frac{\partial v(T)}{\partial t}=\frac{r(p v(T)-c)}{1-e^{-r T}}+\frac{K\left(e^{r T}-1\right)}{e^{r K T}-1}\left[[R(K T, x)-r D]-\frac{r}{1-e^{-r T}}\left[(p v(T)-c) e^{-r T}\right]\right] \\
& K^{c}=\left\{K \in N \underset{K}{\left.\operatorname{Max}_{K} V\left(K, T^{c}(K)\right)\right\}}\right. \\
& R\left(K^{c} T^{c}, x\right) \geq r D+r\left[\frac{e^{-r T^{c}}}{1-e^{-r T^{c}}}\left(p v\left(T^{c}\right)-c\right)\right]
\end{aligned}
$$

Condition (16) is the rotation date condition for a given $K$. It has the same interpretation as the unconstrained private condition (13). Conditions (17) and (18) are the conversion date conditions. Recall that the landowner's private conversion date in the absence of an UGB is given by $K^{p} T^{p}$, satisfying $R(K T, x) \geq r D+r\left[\frac{e^{-r T}}{1-e^{-r T}}(p v(T)-c)\right]$ by (14). Moreover a binding UGB requires that the regulation does not expire before the 
unregulated private conversion date, that is, $t(x)^{U G B}>K^{p} T^{p}$. Otherwise, the UGB would not change any of the plans of the forest landowner and the forester's strategy would be the same as that under no development prohibition. Thus, a binding UGB ensures that $R(K T, x)>r D+r\left[\frac{e^{-r T}}{1-e^{-r T}}(p v(T)-c)\right], \quad \forall K T \geq t(x)^{U G B}$. As a result, with a binding UGB, the landowner converts his land to residential use at $t=t(x)^{U G B}$, which is the date established by the local government.

Given that the landowner optimal conversion time is $K^{c} T^{c}=t(x)^{U G B}$, the optimal strategy $\left\{K^{c}, T^{c}\right\}$ under this policy is such that it satisfies (16). Therefore, we have that:

$$
K^{c}=\frac{t(x)^{U G B}}{T^{c}}
$$

And $T^{c}$ is implicitly determined by:

$$
\begin{aligned}
p \frac{\partial v\left(T^{c}\right)}{\partial t} & =\frac{r}{1-e^{-r T^{c}}}\left(p v\left(T^{c}\right)-c\right)+ \\
& +\frac{K^{c}\left(e^{r T^{c}}-1\right)}{e^{r t(x)^{U G B}}-1}\left[\left[R\left(t(x)^{U G B}, x\right)-r D\right]-\frac{r}{1-e^{-r T^{c}}}\left[\left(p v\left(T^{c}\right)-c\right) e^{-r T^{c}}\right]\right]
\end{aligned}
$$

If properly set, a UGB can delay development in areas outside the urban boundary $\left(T^{D}=K^{p} T^{p}<t(x)^{U G B}\right)$ and temporarily protect land from residential conversion. While an UGB can regulate the type of land use on a plot of land, this instrument does not regulate management practices. As a result, forest management practices outside the boundary will not be socially optimal $\left(T^{c} \neq T^{s p}\right.$ ) since the private landowner does not take into account any of the nontimber benefits from a standing forest when managing his

forestland during the UGB period. Moreover, whether $T^{c} \underset{<}{<} T^{p}$ depends on the net impact 
the regulated conversion date has on the "switching balance" (second term on the righthand-side of (20)). If the impact on the forgone net value derived from residential land use $\left(R\left(t(x)^{U G B}, x\right)-r D\right)$ dominates the impact on timber revenue interests when harvesting at $T^{c}$, the optimal rotation decreases due to concavity of $v(t)$, that is, $T^{c}<T^{p}$. If nontimber benefits are increasing with the age of the forest stand, then an UGB has a negative impact on the provision of old-growth benefits from forestland that actually becomes subject to a temporary development prohibition. ${ }^{26}$

\section{Permanent Development Prohibition}

Let's assume now that there is a greenbelt in place and that our plot of land is located inside the belt. Under this policy forestland can never be converted to residential use, that is, $K \rightarrow \infty$. The maximization problem of the forester is thus reduced to the Faustmann multiple rotation problem.

In contrast to the temporary case, a permanent development prohibition is able to keep forestland from ever being converted to residential use. If nontimber benefits are unrelated to the age of the forest, a greenbelt can also attain the goal of permanently increasing the provision of nontimber benefits associated to the existence of undeveloped land. However, if environmental benefits are related to the age of the forest then our results show that this type of urban containment is also a poor policy to increase the provision of this type of nontimber benefits. Since the forest landowner does not take into account nontimber

\footnotetext{
${ }^{26}$ Even if nontimber benefits are not associated with the age of the stand and are just related with the existence of undeveloped land, it is not certain whether an UGB can actually protect land from urban conversion and preserve open space. Imposition of an UGB implies that local governments can guess correctly when it would be socially efficient to convert land into urban use. As mentioned in Brueckner (2001), without a careful inquiry into the sources of market failure leading to urban sprawl, there is a danger that an UGB may be too stringent. And if that is the case, then the UGB would lead to an inappropriate escalation of housing costs and unwarranted increases in density, decreasing society's welfare.
} 
benefits from the forest when choosing the optimal length of a forest cycle, the private rotation period (in this case the Faustmann rotation date) is not socially optimal. ${ }^{27}$

\subsection{Threat of Development Prohibition}

Next, consider the case where an urban containment policy has not been imposed yet at $t=0$. Until it actually occurs, the policy is just a threat to the landowner. The type and future location of the urban containment policy is known with certainty by the landowner. However, the point in time at which the development restriction by the policy is imposed on the property is uncertain. ${ }^{28}$ Thus, prior to the implementation of the urban containment policy, a landowner beyond the (then future) boundary knows that he has the right to develop the land now, but will lose or have most of his development rights reduced when the urban containment policy goes into effect.

Following Turnbull (2005), our regulatory environment is now represented by a stochastic survival model. Let $\theta(x) g(t)$ represent the probability that a development prohibition is imposed by time $t$ and $\theta(x) \frac{\partial g(t)}{\partial t}$ the probability that the development prohibition is imposed at $t$, with $\theta(x)$ a positive nonstochastic parameter used to capture changes in the probability structure.

\footnotetext{
${ }^{27}$ Regulations under the Federal Clean Water Act, Clean Air Act and the Endangered Species Act can help improve the environmental performance of forestry operations by directly regulating management activities. For example, if an endangered species is found in an area where timber is harvested, the ESA may be used to place a moratorium on timber harvest. But on the other hand, because they reduce the private owner's ability to realize value from a working forest, private forest owners might be compelled to consider other uses for their forests (for example agriculture). What actually happens on forested land depends on a set of policy interrelations and policy coordination. Further consideration of this point is warranted, but goes beyond the scope of this paper, and so is left for future work.

${ }^{28}$ Landowners can be well informed about the future location of an UGB long before it is actually imposed due to public meetings and press coverage of the political charged process.
} 
We assume $\theta(x) \frac{\partial g(t)}{\partial t}$ to be positive, which reflects that the longer the landowner waits before harvesting, the more likely that he will lose the possibility to convert land. Also, the dependence of the non-stochastic parameter on location $(x)$ reflects that land can be a source of different types of open space externality. Hence, a greater value of $\theta(x)$ implies a greater probability of the development restriction being imposed on the landowner by time $t$ because the plot of land at location $x$ has been identified as being a source of a particular environmental externality.

\section{Threat of Temporarily Development Prohibition}

Before we modify the objective function of the landowner under the possibility of a binding UGB set at some $t \leq K^{p} T^{p}$, begin by noting that the maximum present value of returns to the land at location $x$ when an UGB is imposed at some $t$ prior to the land being converted to residential use is given by:

$$
\begin{aligned}
& V\left(\tilde{T}, t, t(x)^{U G B}\right)=-c_{0}+e^{-r \tilde{T}}(p v(\tilde{T})-c) \frac{1-e^{-r\left(t+t(x)^{U G B}\right)}}{1-e^{-r \tilde{T}}}+ \\
& +\int_{t+t(x)^{U G B}}^{\infty} R(s, x) e^{-r s} d s-D e^{-r\left(t+t(x)^{U G B}\right)}
\end{aligned}
$$

where $\tilde{T}$ is the optimal private rotation date when an UGB is set at time $t, t(x)^{U G B}$ is the time length of the UGB and $K^{p} T^{p}$ is the private optimal conversion date in the absence of any threat. The optimal conversion date when an UGB is set at time $t$ satisfies $\tilde{K} \tilde{T}=t+t(x)^{U G B}>K^{p} T^{p} \cdot{ }^{29}$

\footnotetext{
${ }^{29}$ Setting $t=0$, (21) simplifies to (15), which is the present value of returns to the land when a binding UGB occurs at $t=0$. In this case, $\tilde{K} \tilde{T}=K^{c} T^{c}$.
} 
At $t=0$ the landowner's expected returns to his plot of land takes into account the possible conditional development strategy $\left\{t(x)^{U G B}, \tilde{T}\right\}$ in the event the constraint is imposed at some $t \leq K^{p} T^{p}$. Under this threat, the landowner's objective function can be expressed as:

$$
\begin{aligned}
& V^{T U}(K, T)=(1-\theta(x) g(K T))\left[e^{-r T}(p v(T)-c) \frac{1-e^{-r K T}}{1-e^{-r T}}-c_{0}+\int_{K T}^{\infty} R(t, x) e^{-r t} d t-D e^{-r K T}\right]+ \\
& \quad+\int_{0}^{K T} \theta(x) \frac{\partial g(t)}{\partial t} V\left(\tilde{T}, t, t(x)^{U G B}\right) d t
\end{aligned}
$$

The first term on the right-hand-side of (22) is the present value of the returns to land weighted by the probability that the land is not prohibited from residential conversion prior to $K T$. The second term on the right-hand-side of (22) takes into account the likelihood that land at location $x$ be under a development prohibition at some time between $t=0$ and $t=K T$. Note that $V\left(\tilde{T}, t, t(x)^{U G B}\right)$ is the present value of returns to land from $t$ onwards, given that land at location $x$ is prohibited from being converted until time $t+t(x)^{U G B}$. Weighting this term by the probability that land is prohibited at time $t$ to be converted to residential use and integrating over $[0, K T]$, yields the expected value of the private returns to the land in that case. The optimal rotation date given $K, T^{t u}(K)$, satisfies the following condition:

$$
\begin{aligned}
& p \frac{\partial v(T)}{\partial T}=\frac{r(p v(T)-c)}{1-e^{-r T}}+ \\
& +\frac{K\left(e^{r T}-1\right)}{e^{r K T}-1}\left[R(K T, x)-r D-\frac{r}{1-e^{-r T}}(p v(T)-c) e^{-r T}\right]+ \\
& +\frac{\theta(x) \frac{\partial g(K T)}{\partial t} K}{1-\theta(x) g(K T)}\left[V^{P}\left(K^{p}, T^{p}\right)-V\left(\tilde{T}, K T, t(x)^{U G B}\right]\right.
\end{aligned}
$$


The optimality condition in (23) has a simple interpretation that is best seen when it is compared to equation (13) and is different only because of the additional term associated with the threat of a temporary development prohibition. The risk that conversion to residential use will be constrained by a temporary development prohibition is measured by $\frac{\theta(x) \frac{\partial g(K T)}{\partial t} K}{1-\theta(x) g(K T)}$ which represents the hazard rate, that is, the probability that a development prohibition is imposed at $t=K T$, given that land has survived to that prohibition up to that time. For better insight, equation (23) can be re-written as:

$$
\frac{\partial V^{P}(K, T)}{\partial T}=\frac{\theta(x) \frac{\partial g(K T)}{\partial t}}{1-\theta(x) g(K T)} K\left[V^{P}(K, T)-V\left(\tilde{T}, K T, t(x)^{U G B}\right)\right]
$$

It is clear from inspection of (24) and (13) that, for a given $K$, optimal rotation decreases with a potential temporary development prohibition, that is, $T^{t u}<T^{p} \cdot{ }^{30}$ Given the threatened loss of residential rents during an UGB ban, the landowner's optimal response is to anticipate harvesting dates, sacrificing some timber revenues but at the same time increasing the probability that the private planned conversion of forestland to residential use will be allowed to take place without delay. In particular, we would have an earlier conversion to residential use as a result of the threat, $K T^{t u}<K T^{p}$. This result implies, nevertheless, the landowner cannot adjust the number of rotation cycles.

When $K$ can be adjusted, the net impact of a potential development prohibition on private conversion date is ambiguous. Note first that the probability that a development restriction is imposed by time $t$ increases over time $\left(\frac{\partial g(t)}{\partial t}>0\right)$. If $K^{t u} \leq K^{p}$, the impact on

\footnotetext{
${ }^{30}$ The right-hand side of (24) is positive since $\frac{\partial g(K T)}{\partial t}>0$ and $V^{P}\left(K^{p}, T^{p}\right)>V\left(\tilde{T}, K^{p} T, t(x)^{U G B}\right)$, while
} in the unconstrained case the right-hand side of (24) is zero. 
the number of rotation cycles reinforces the effect of shorter rotations on conversion date, anticipating conversion time. If $K^{t u}>K^{p}$ then a countervailing effect from increasing the number of rotation cycles may dominate, postponing conversion time. Since conversion to residential use occurs at the end of a rotation cycle, the optimal response may be to have more rotation cycles of shorter length. ${ }^{31}$ As a result, unregulated forestland may be converted later in the presence of a potential development prohibition. ${ }^{32}$ This result contrasts with previous results that show that a threat of a development prohibition unambiguously hasten urban development (Turnbull (2004, 2005)).

\section{Threat of Permanent Development Prohibition}

Now let's assume there is a threat of a permanent development prohibition at some $t \leq K^{p} T^{p}$. In this case, the expected present value of returns to the land can be expressed

as:

$$
\begin{aligned}
V^{P U}(T, K) & =\frac{[p v(T)-c] e^{-r T}}{1-e^{-r T}}-c_{0}+ \\
& +(1-\theta(x) g(K T))\left\{\int_{K T}^{\infty} R(t, x) e^{-r t} d t-\frac{[p v(T)-c] e^{-r T(K+1)}}{1-e^{-r T}}-D e^{-r K T}\right\}
\end{aligned}
$$

where $\theta(x) g(K T)$ represents the probability that a permanent development prohibition is imposed by time $K T$.

\footnotetext{
${ }^{31}$ An increase in $K$ increases the riskiness of the investment returns from waiting to convert land into an urban use. This effect, on its own, would speed the date of conversion. But an increase in $K$ has other effects that work to delay development. Since a decrease in rotation length decreases the hazard rate, the increase in the number of rotation cycles can help to recover some of the timber revenue losses from anticipating rotation date. The net effect on the rotation date is thus ambiguous.

${ }^{32}$ Let $K^{t u}$ be the optimal rotation cycles in the presence of a threat of a temporary development prohibition. Given that $T^{t u}<T^{p}$ for a given $K$, this implies that $K^{t u} T^{t u}<K^{t u} T^{p}$. On the other hand, if $K^{t u} T^{t u}>K^{p} T^{p}$ and if $T^{t u}<T^{p}$, then it must be the case where $K^{t u}>K^{p}$.
} 
According to (25), the landowner is guaranteed the present value of timber revenue over infinite cycles of rotations (that is, the value of land under the Faustmann setting, $V^{F}(T)$ ), regardless of the development restriction. The landowner can, however, earn the increment from residential development, but only if land is converted to residential use before the permanent prohibition is put into place. Thus, this increment from residential use is weighted by the probability that no permanent prohibition has been imposed before the conversion time. The optimal landowner strategy is the $\left\{K^{p u}, T^{p u}\right\}$, satisfying the following conditions:

$$
\begin{aligned}
& \frac{\partial V^{P}(K, T)}{\partial T}=\frac{\theta(x) K \frac{\partial g(K T)}{\partial t}}{(1-\theta(x) g(K T))}\left[V^{P}(K, T)-V^{F}(T)\right] \\
& K^{p u}=\left\{K \in N: \underset{K}{\left.\operatorname{Max} V\left(K, T^{p u}(K)\right)\right\}}\right. \\
& R\left(K^{p u} T^{p u}, x\right) \geq r D+r\left[\frac{e^{-r T^{p u}}}{1-e^{-r T^{p u}}}\left(p v\left(T^{p u}\right)-c\right)\right]
\end{aligned}
$$

Conditions (27) and (28) are related to the date of land conversion and have the same interpretations as before. Equation (26) is the rotation date condition, which is modified for the risk of a permanent development prohibition. ${ }^{33}$ For a given $K$, this risk increases the marginal cost of letting a stand grow in terms of forgone value derived from future conversion to residential use. Therefore, rotation cycles are shorter compared to the

\footnotetext{
${ }^{33}$ In the absence of policy uncertainty ( $g(K T)=0$ ), equation (26) becomes the first-order condition of the forester's unconstrained problem, (13). On the other hand, if the forested land can never be converted to any urban use $(g(K T)=1)$, equation (26) shows that the private landowner problem is the Faustmann maximization problem $\left(V^{P}(K, T)=V^{F}(T)\right)$.
} 
unconstrained case $\left(\frac{\partial V^{P}(K, T)}{\partial T}=0\right)$ since $V^{P}(K, T)>V^{F}(T)$ and $\frac{\partial g(K T)}{\partial t}>0 .{ }^{34}$ Moreover, shorter rotation dates imply earlier conversion of unregulated forestland than otherwise $\left(K T^{u}<K T^{p}\right)$. Like in the previous case, if the number of rotation cycles can be adjusted, the net effect of a potential permanent development prohibition on forestland conversion is ambiguous. A comparison between (26) and (24) reveals nevertheless that forestland will be converted earlier under a threat of a permanent development prohibition than under a potential temporary development ban as long as $V\left(\tilde{T}, K T, t(x)^{U G B}\right)>V^{F}(T)$. Moreover, a comparison between the generalized procedure in table 3:Appendix-A and table 4:Appendix-A also reveals that if forest management practices are exogenous, then anticipated urban containment policies can narrow real options in land markets and potentially accelerate land development.

Finally, different types of land can differ on their likelihood of being prevented from development. To assess the permanent development prohibition effect on rotation dates, totally differentiate equation (26) and for better insight, evaluate at $\theta(x)=0$ :

$$
\frac{d T^{p u}}{d \theta(x)}=\frac{K \frac{\partial g(K T)}{\partial t}\left[V^{P}(K, T)-V^{F}(T)\right]}{\frac{\partial^{2} V^{P}(K, T)}{\partial T^{2}}}<0
$$

As $\theta(x)$ increases (for example because land generates larger environmental externalities), the shorter will be the optimal rotation. The reason is because as $\theta(x)$ increases, the probability of a permanent development prohibition increases, which creates

\footnotetext{
${ }^{34}$ The behavior of $g(t)$ over time can reflect that the longer the landowner waits before harvesting, the more likely that he will lose the possibility to convert land because endangered species may move to old growths, which may trigger regulation. In our model, nontimber benefits from older trees occur when $F(t)$ is increasing over time. Thus, as stand age increases, the probability of endangered species inhabitation and permanent development prohibition increases, causing a decrease in the age at which the forest is harvested.
} 
a greater incentive to preempt the regulation with earlier clear-cuts, destroying those characteristics of the land (in this case the size of the trees) that would trigger the regulation.

\section{Conclusions}

Developing better land-use decision making models is extremely important as policy makers increase reliance on land use conversion policies to achieve environmental goals such as habitat preservation and carbon sequestration through better management of forests. This paper presents a model of a single forest landowner that allows for switching between forest and residential development at some point in the future and takes into account standage-dependent nontimber benefits. Within this framework, we examine the impact of actual and anticipated urban containment policies on the protection and use of private real property to achieve environmental goals. While our model is developed to account for the specific case of residential use at some point in the future, the model is more broadly applicable to other situations such as reversible conversion decisions to agriculture.

All else being equal, a large undeveloped forest landscape usually is perceived as offering better scenery, more and less crowded recreation opportunities, and greater habitat and resource protection than a smaller more-developed forest landscape. As such more populated and rapidly growing communities and states have engaged in urban containment policies aiming to manage urban growth and protect open space.

Our results show nevertheless that without both land protection from conversion to irreversible uses and effective land management practices, social values associated to the age of a private forest stand cannot be achieved. Moreover, policymakers should take into account the interdependencies between alternative land uses when setting incentives for 
private landowners to preserve forestland. The reason is because these interdependencies create feedback effects, which affect private landowners' management decisions.

Urban containment policies can have positive environmental impacts by forbidding or delaying development, but do not regulate management practices. In particular, greenbelts offer more permanent forestland protection than UGBs. However, if environmental benefits are related to the age of the forest, our results show that both UGBs and Greenbelts are poor instruments to increase the provision of such benefits. In general, these results hold under certainty as well as under uncertainty to the time at which a development prohibition is imposed. Even though it is always optimal to anticipate harvesting time to avoid potential development prohibitions, the private landowner may optimally choose to convert later his forestland by adjusting the number of rotation cycles. This effect cannot be captured if the opportunity cost of the current use of land is taken as exogenous. Our results thus imply that integrated land-use policies will maximize forests nontimber benefits.

Finally, we also show that forestland conversion decisions should be based on real option theory and not on the traditional net present value rule even in a context of certainty. In particular, our results show that the net present value bias conversion decisions towards immediate development.

There are a couple of ways in which our model might be explored in future research. We have considered optimal management practices at the timber stand level, abstracting away from the impact that changing management practices might have on equilibrium prices at higher levels of scale. Moreover, we focused on clear-cut harvesting. Other types of harvesting practices such as partial harvesting can have different impacts on the provision of nontimber benefits. Finally, often, forest use competes with agriculture, implying that conversion to an alternative use does not necessarily involve deforestation. 


\section{References}

Alig, R., A. Plantinga, D. Haim, and M. Todd, “Area Changes in U.S Forests and Other Major Land Uses, 1982 to 2002, with Projections to 2062”. Gen. Tech. Rep. PNWGTR815. Portland, OR: U.S. Department of Agriculture, Forest Service, Pacific Northwest Research Station. 98 p, 2010.

Arnott, R., A Simple Urban Growth Model with Durable Housing, Regional Science and Urban Economics 10(1) (1980) 53-76.

Barlow, S. A., I. A. Munn, D. A. Cleaves, and D. L. Evans, The Effects of Urban Sprawl on Timber Harvesting, Journal of Forestry 96 (12) (1998) 10-14.

Brueckner, J.K., Urban sprawl: Lessons from Urban Economics. In: W.G. Gale, J.R. Pack (Eds.), Brookings-Wharton Papers on Urban Affairs, Brookings Institution Press, Washington, DC, (2001) 65-89.

Brueckner, J.K., Urban Sprawl: Diagnosis and Remedies. International Regional Science Review, 23(2) (2000a) 160-171.

Brueckner, J. K., "Urban Growth Models with Durable Housing: An Overview”. In: Huriot J M, Thisse J F (eds.) Economics of Cities: Theoretical Perspectives. Cambridge University Press, Cambridge, 2000b.

Brueckner, J. K., Growth Controls and Land Values in an Open City, Land Economics 66 (3) (1990) 237-248.

Capozza D. and R. Helsley, The Fundamentals of Land Prices and Urban Growth, Journal of Urban Economics 26 (1989) 295-306.

Capozza D. and R. Helsley, The Stochastic City, Journal of Urban Economics 28 (2) (1990) 187-203.

Capozza D., and Y. Li, The Intensity and Timing of Investment: The Case of Land, American Economic Review 84 (1994) 889-940.

Capozza, D. R., and G. Sick, The Risk Structure of Land Markets, Journal of Urban Economics 35 (1994) 297-319.

Capozza, D. R., and Y. Li, Optimal Land Development Decisions, Journal of Urban Economics 51 (1) (2002) 123-142.

Conrad, J.M., Analysis on the Option Value of Old-Growth Forest, Ecological Economics 22 (1997) 97-102.

Dixit A., and R. Pindyck, Investment under Uncertainty, Princeton University Press, (1994). 
Englin J.E, and M.K. Klan, Optimal Taxation: Timber and Externalities, Journal of Environmental Economics and Management 18 (1990) 263-275.

Fujita, M., Spatial Patterns of Residential Development, Journal of Urban Economics 12 (1) (1982) 22-52.

Geoghegan, J., The value of open spaces in residential land use, Land Use Policy 19 (1) (2002) 91-98.

Hartman, R., The Harvesting Decision when a Standing Forest Has Value, Economic Inquiry 14 (1976) pp 52-58.

Irwin, E.G., The effects of open space on residential property values, Land Economics 78 (4) (2002) 465-480.

Kline, J.D., D.L. Azuma, and R.J. Alig, Population growth, urban expansion, and private forestry in Western Oregon, Forest Science 50 (1) (2004) 33-43.

Leggett, C., and N. Bockstael, Evidence of the Effects of Water Quality on Residential Land Prices, Journal of Environmental Economics and Management 39 (2000) 121-144.

Munn, I., S. Barlow, D. Evans, and D. Cleaves, Urbanization's Impact on Timber Harvesting in the South Central United States, Journal of Environmental Management 64 (2002) 65-76.

Pendall, R., J. Martin, and W. Fulton. Holding the line: urban containment in the United States. Center on Urban and Metropolitan Policy, The Brookings Institution, Washington, D.C.,USA. 2002.

Reed, W. J., The Decision to Conserve or Harvest Old-Growth Forest, Ecological Economics 8 (1993) 45-69.

Strang, W., On the Optimal Harvesting Decision, Economic Inquiry 21 (1983) 401-423.

Swallow, Stephen K., Peter J. Parks, and David N. Wear, Policy-relevant non-convexities in the production of multiple forest benefits. Journal of Environmental Economics and Management 19 (3) (1990) 264-280.

Turnbull, G., The Investment Incentive Effects of Land Use Regulations, The Journal of Real Estate Finance and Economics 31 (4) (2005) 357-395.

Turnbull, G., Urban Growth Controls: Transitional Dynamics of Development Fees and Growth Boundaries, Journal of Urban Economics 55 (2004) 215-237.

Turnbull, G., Land Development under the Threat of Taking. Southern Economic Journal 69 (2002) 468-501. 
Tyrvainen, L., and A. Miettinen, Property Prices and Urban Forest Amenities, Journal of Environmental Economics and Management 39 (2002) 205-223.

Van Kooten, G.C., C.S. Binkley, and G. Delcourt, Effects of Carbon Taxes and Subsidies on Optimal Forest Rotation Age and Supply of Carbon Services, American Journal of Agricultural Economics 77 (1995) 365-374.

Wear, D.N., R. Liu, J.M. Foreman, and R.M. Sheffield, The effects of population growth on timber management and inventories in Virginia, Forest Ecology and Management 118 (1999) 107-115.

\section{Appendix A}

Table 1: Alternative Criteria for Determining Rotation Date under Certainty

\begin{tabular}{|c|c|}
\hline $\begin{array}{l}\text { Objective } \\
\text { Maximize }\end{array}$ & First-Order Condition with respect to $T$ \\
\hline $\begin{array}{l}\text { Net present value of } \\
\text { timber } \\
\text { (Faustmann, } K \rightarrow \infty \text { ) }\end{array}$ & $p \frac{\partial v(T)}{\partial t}=\frac{r(p v(T)-c)}{1-e^{-r T}}$ \\
\hline $\begin{array}{l}\text { Present value of timber } \\
\text { plus nontimber benefits } \\
\text { (Hartman, } K \rightarrow \infty \text { ) }\end{array}$ & $\begin{array}{l}p \frac{\partial v(T)}{\partial t}=\frac{r(p v(T)-c)}{1-e^{-r T}}+ \\
+\left[\frac{r \int_{0}^{T} F(t) e^{-r t} d t}{1-e^{-r T}}-F(T)\right.\end{array}$ \\
\hline $\begin{array}{l}\text { Present value of timber } \\
\text { plus nontimber benefits } \\
\text { plus present value of } \\
\text { residential rents net } \\
\text { conversion costs } \\
(0 \leq K \leq \infty)\end{array}$ & $\begin{array}{l}p \frac{\partial v(T)}{\partial t}=\frac{r}{1-e^{-r T}}(p v(T)-c)+ \\
+\left[\frac{r \int_{0}^{T} F(t) e^{-r t} d t}{1-e^{-r T}}-F(T)\right]+ \\
+\frac{K\left(e^{r T}-1\right)}{e^{r K T}-1}\left[[R(K T, x)-r D]-\frac{r\left[(p v(T)-c) e^{-r T}+\int_{0}^{T} F(t) e^{-r t} d t\right.}{1-e^{-r T}}\right.\end{array}$ \\
\hline
\end{tabular}


Table 2: Rule for Optimal Conversion Date for Society (including nontimber benefits) under Certainty

\begin{tabular}{|c|c|}
\hline Criteria & $\begin{array}{c}\text { Decision Rule for Immediate Conversion } \\
\text { Functional Form }{ }^{c} \\
R(t, x)=R(0, x) e^{\alpha t}\end{array}$ \\
\hline $\begin{array}{l}\text { Generalized Procedure } \\
\text { where } r^{\prime} \text { is the constant rate } \\
\text { at which the landowner } \\
\text { discounts future rents and } \\
\alpha \text { is the growth rate of } \\
\text { residential rents. }\end{array}$ & $\begin{array}{l}\frac{R(0, x)}{r^{\prime}-\alpha}-D-\frac{(p v(T(K))-c) e^{-r^{\prime} T(K)}}{1-e^{-r^{\prime} T(K)}} \geq \frac{1-e^{r^{\prime} K T(K)}}{1-e^{-r^{\prime} T(K)}} \int_{0}^{T(K)} F(t) e^{-r t} d t+ \\
+\left[\frac{R(0, x) e^{\alpha K T(K)}}{r^{\prime}-\alpha}-D-\frac{(p v(T(K))-c) e^{-r^{\prime} T(K)}}{1-e^{-r^{\prime} T(K)}}\right] e^{-r^{\prime} K T(K)}\end{array}$ \\
\hline
\end{tabular}

Table 3: Alternative Criteria for Determining Conversion Date for the Private Landowner (ignoring nontimber benefits) under Certainty

\begin{tabular}{|c|c|}
\hline Criteria & $\begin{array}{c}\text { Decision Rules for Immediate Conversion } \\
\text { Functional Form }{ }^{c} \\
R(t, x)=R(0, x) e^{\alpha t}\end{array}$ \\
\hline $\begin{array}{l}\text { Conventional Procedure }{ }^{a} \\
\text { Forest Models }\left(T^{D}=0 \Rightarrow K=0\right) \\
\text { Conversion should take place } \\
\text { immediately if the net present value } \\
\text { (NPV) is positive }\end{array}$ & $\frac{R(0, x)}{r^{\prime}-\alpha}-D-\frac{\left(p v\left(T^{F}\right)-c\right) e^{-r^{\prime} T^{F}}}{1-e^{-r^{\prime} T^{F}}} \geq 0$ \\
\hline $\begin{array}{l}\text { Conventional Procedure } \\
\text { Urban growth models with } \\
\text { irreversible investments and } \\
\text { conversion costs }{ }^{b} \\
\text { Forest: } T^{D}>0, T \text { exogenous, } \\
0<K<\infty \\
\text { Agriculture: } T^{D}>0, r_{a} \text { exogenous, } \\
0<K<\infty \\
\text { A positive NPV is necessary but not } \\
\text { sufficient for optimal immediate } \\
\text { conversion. The option of waiting to } \\
\text { convert must also be evaluated. } \\
\text { Prior to conversion date ( } t<T^{D} \text { ) } \\
\text { option value is positive and at the } \\
\text { conversion date the option value is } \\
\text { zero }\left(t=T^{D} \text { ). }\right.\end{array}$ & $\begin{array}{l}\text { Forest as the alternative use: } \\
\frac{R(0, x)}{r^{\prime}-\alpha}-D-\frac{\left(p v\left(T^{F}\right)-c\right) e^{-r^{\prime} T^{F}}}{1-e^{-r^{\prime} T^{F}}} \geq \\
{\left[\frac{R(0, x) e^{\alpha K T^{F}}}{r^{\prime}-\alpha}-D-\frac{\left(p v\left(T^{F}\right)-c\right) e^{-r^{\prime} T^{F}}}{1-e^{-r^{\prime} T^{F}}}\right] e^{-r^{\prime} K T^{F}}} \\
\text { Agriculture as the alternative use: } \\
\frac{R(0, x)}{r^{\prime}-\alpha}-D-\frac{r_{a}}{r^{\prime}} \geq \\
{\left[\frac{R(0, x) e^{\alpha T^{D}}}{r^{\prime}-\alpha}-D-\frac{r_{a}}{r^{\prime}}\right] e^{-r^{\prime} T^{D}}}\end{array}$ \\
\hline
\end{tabular}




\begin{tabular}{|l|l|}
\hline $\begin{array}{l}\text { Generalized Procedure }^{b} \\
T^{D}>0, T \text { endogenous, } 0<K<\infty\end{array}$ & $\begin{array}{l}\frac{R(0, x)}{r^{\prime}-\alpha}-D-\frac{(p v(T(K))-c) e^{-r^{\prime} T(K)}}{1-e^{-r^{\prime} T(K)}} \geq \\
\begin{array}{l}\text { Endogenous forest management } \\
\text { practices and feedback effects from } \\
\text { changes in } K \text { affect both the NPV } \\
\text { (left-hand-side) and the option value } \\
\text { of waiting (right-hand-side) }\end{array}\end{array}$
\end{tabular}

${ }^{a}$ For convenience we set $c_{0}=0$.

${ }^{b}$ We assume an interior solution for $K$ if land is not converted immediately. For convenience we also set $c_{0}=0$.

${ }^{c}$ This functional form is chosen because it is a flexible functional form that is twice differentiable and integrable.

Table 4: Alternative Criteria for Determining Conversion Date for the Private Landowner (ignoring nontimber benefits) in the Presence of a threat of a Development Prohibition

\begin{tabular}{|c|c|}
\hline Threat $^{a}$ & $\begin{array}{c}\text { Decision Rules for Immediate Conversion } \\
\text { Functional Form }{ }^{c} \\
R(t, x)=R(0, x) e^{\alpha t}\end{array}$ \\
\hline $\begin{array}{l}\text { Policy uncertainty } \\
\text { decreases the value of } \\
\text { the option to delay } \\
\text { conversion, that is, the } \\
\text { option value }\end{array}$ & $\begin{array}{l}\frac{R(0, x)}{r^{\prime}-\alpha}-D-\frac{(p v(T(K))-c) e^{-r^{\prime} T(K)}}{1-e^{-r^{\prime} T(K)}} \geq \\
\left(1-\theta(x) g(K T(K))\left[\frac{R(0, x) e^{\alpha K T(K)}}{r^{\prime}-\alpha}-D-\frac{(p v(T(K))-c) e^{-r^{\prime} T(K)}}{1-e^{-r^{\prime} T(K)}}\right] e^{-r^{\prime} K T(K)}\right. \\
\text { where } r^{\prime} \text { is the constant rate at which the landowner discounts future rents } \\
\text { and } \alpha \text { is the growth rate of residential rents. }\end{array}$ \\
\hline $\begin{array}{l}\text { Temporary } \\
\text { Development } \\
\text { Prohibition }\end{array}$ & $\begin{array}{l}\frac{R(0, x)}{r^{\prime}-\alpha}-D-\frac{(p v(T(K))-c) e^{-r^{\prime} T(K)}}{1-e^{-r^{\prime} T(K)}} \geq \\
\left(1-\theta(x) g(K T(K))\left[\frac{R(0, x) e^{\alpha K T(K)}}{r^{\prime}-\alpha}-D-\frac{(p v(T(K))-c) e^{-r^{\prime} T(K)}}{1-e^{-r^{\prime} T(K)}}\right] e^{-r^{\prime} K T(K)}+\right. \\
+\int_{0}^{K T(K)} \theta(x) \frac{\partial g(t)}{\partial t} V\left(\tilde{T}, t, t(x)^{U G B}\right) d t-\theta(x) g(K T(K)) \frac{(p v(T(K))-c) e^{-r^{\prime} T(K)}}{1-e^{-r^{\prime} T(K)}}\end{array}$ \\
\hline
\end{tabular}

${ }^{a}$ We assume no nontimber benefits, an interior solution for $K$ if $K \neq 0$. For convenience we also set $c_{0}=0$.

\section{Appendix B}

The analytical derivations of equations (3), (8) and (13). 
Equation (3). The housing bid rent is determined via the open-city assumption, under which the time path of utility is given by an exogenous function $U(t)$. Substituting for $g$ using the budget constraint, the representative urban resident achieves utility $\bar{U}(t)$ when $b$ satisfies the equation:

$$
U(y(t)-b-z(t) x, 1)=\bar{U}(t)
$$

Equation (B1) implies that in equilibrium, utility must be identical regardless where an urban resident lives; otherwise, some urban residents will have an incentive to move. Equation (B1) also implicitly defines the housing bid rent function as:

$$
b(t, x)=b(y(t)-z(t) x, 1), \bar{U}(t))
$$

that is, equation (3).

Equations (8) and (13). By maximizing (7) with respect to $T$, for a given $K$, we obtain:

$$
\begin{aligned}
& \frac{\left(1-e^{-r K T}\right) e^{-r T}}{1-e^{-r T}} p \frac{\partial v(t)}{\partial t}-(p v(T)-c) \frac{r e^{-r T}}{1-e^{-r T}}+ \\
& +e^{-r T} F(T)-\frac{r e^{-r T}}{1-e^{-r T}} \int_{0}^{T} F(t) e^{-r t} d t+(p v(T)-c) \frac{r e^{-r T} K e^{-r K T}}{1-e^{-r T}}+ \\
& +K^{-r K T}\left[\frac{r}{1-e^{-r T}} \int_{0}^{T} F(t) e^{-r t} d t-(R-r D)\right]=0
\end{aligned}
$$

Dividing (B3) by $\frac{\left(1-e^{-r K T}\right) e^{-r T}}{1-e^{-r T}}$ and rearranging the terms noting that $\frac{\left(1-e^{-r T}\right) K e^{-r K T}}{\left(1-e^{-r K T}\right) e^{-r T}}=\frac{e^{r T}-1}{e^{r K T}-1} K$, yields equation (8).

In the case of the private landowner's problem a similar derivation can be undertaken, except that the externalities' terms are not present. So, (13) is obtained. 